\title{
Lung Ultrasound in Community-Acquired Pneumonia and in Interstitial Lung Diseases
}

\author{
Angelika Reissig $^{a}$ Roberto Copetti ${ }^{b}$ \\ ${ }^{a}$ Department of Internal Medicine I, Pneumology and Allergology, Jena University Hospital, Friedrich Schiller \\ University Jena, Jena, Germany; ${ }^{\text {b} E m e r g e n c y ~ D e p a r t m e n t, ~ L a t i s a n a ~ G e n e r a l ~ H o s p i t a l, ~ L a t i s a n a, ~ I t a l y ~}$
}

\section{Key Words}

Acute respiratory distress syndrome $\cdot$ Community-acquired pneumonia - Diffuse parenchymal lung diseases · Lung ultrasound $\cdot$ Pneumonia patients · Pulmonary edema

\begin{abstract}
Lung ultrasound (LUS) is an accurate tool for the diagnosis and follow-up of pneumonia in adults as well as in children. LUS is at least as accurate as chest radiography in diagnosing pneumonia. The most important parenchymal criterion is the positive air bronchogram within an echopoor area. Among pleural criteria, basal effusion was most often detected. The presence of multiple diffuse bilateral B-lines on lung examination indicates the interstitial syndrome (IS). For further differential diagnosis, an integrated consideration of history, clinical examination, LUS and echocardiography should be performed. LUS is an excellent tool for IS screening. Repeated LUS control examinations may reflect the dynamics of IS under therapy and so LUS may serve as a therapy guide.

(c) 2014 S. Karger AG, Basel
\end{abstract}

\section{Introduction}

Community-acquired pneumonia (CAP) remains the leading cause of death from infections in most developed countries [1]. In Germany, the overall incidence of CAP is estimated to reach $400,000-600,000$ cases per year, with a mortality rate of up to $13-14 \%$ for hospitalized patients [2]. In adults, the diagnosis of CAP is confirmed if a new infiltrate on chest X-ray is established. Nevertheless, due to the limitations of chest radiographs, computed tomography (CT) of the thorax is the gold standard for diagnosing CAP.

CAP also plays an important role in children because it is responsible for many deaths in children under 5 years of age in developing countries and for a substantial portion of diseases in developed countries [3]. In contrast to adults, the diagnosis of CAP in children is only based on clinical criteria. Chest radiographs are only recommended

Previous articles in this series: 1 . Herth FJF, Kreuter M: Ultrasound in pulmonology. Respiration 2014;87:1-2. 2. Gompelmann D, Herth FJF: Role of endobronchial and endoscopic ultrasound in pulmonary medicine. Respiration 2014;87:3-8. 3. Kreuter M, Mathis G: Emergency ultrasound of the chest. Respiration 2014;87:89-97.

\section{KARGER}

E-Mail karger@karger.com www.karger.com/res
C 2014 S. Karger AG, Basel

0025-7931/14/0873-0179\$39.50/0
Angelika Reissig, MD

Department of Internal Medicine, Pneumology and Allergology

Medical Clinic I, Friedrich Schiller University

Erlanger Allee 101, DE-07740 Jena (Germany)

E-Mail angelika.reissig@med.uni-jena.de 
in severe cases treated in hospital or if complications occur $[4,5]$. Therefore, it has been shown that $>80 \%$ of children with clinical suspicion of CAP cannot be confirmed radiologically $[6,7]$, leading to unnecessary antibiotic therapy. Therefore, lung ultrasound (LUS) has become important for the diagnosis and follow-up of pneumonia in adults as well as in children in the last years $[8,9]$.

Although CT would be the best reference standard for all sonographically diagnosed pneumonia, it is only applied in adults in case of discrepant X-ray results in two planes [9]; in children, normally chest X-ray in only one plane serves as the reference [8].

In this article, interstitial lung diseases cover diffuse parenchymal lung diseases (DPLD; different kinds of fibrosis) as well as interstitial pneumonia, acute respiratory distress syndrome (ARDS) and acute heart failure because LUS becomes more and more important in rapid decision making regarding these entities.

\section{Technique of LUS}

LUS may be performed with a usual ultrasound machine. At present, there are no data for establishing the best scanner settings in order to better visualize abnormal lesions and artifacts. For the examination of adult patients, convex, microconvex and linear probes are generally employed, while linear probes are preferred in children. The linear probe is the best choice for studying the dynamics of breath-dependent motion as well as pleural line abnormalities.

The patient may be evaluated in a sitting or supine position. This depends on the clinical condition of the patient as well as on the clinical problem. In most cases, dorsal regions are evaluated in the sitting patient, while anterior regions are assessed in the supine position. Pleural effusion is best detected in the sitting position, while the supine position is favored for a pneumothorax.

In general, image acquisition may be performed for the evaluation of the whole lung or as focal investigation when a clinicopathological finding is detected. Panoramic evaluation is achieved by performing longitudinal scans, from top to bottom, along the anatomical lines of the thorax (parasternal, midclavicular axillary and paravertebral lines) as well as horizontal scans along the intercostal spaces. A focal examination is performed with different scans (longitudinal, transverse and oblique views) and sometimes also with different probes. Often, the examination begins in symptomatic areas, for example, where the patient complains of pleuritic pain or where a pathological finding is present on auscultation or percussion. In patients with a forced supine position, posterior areas may be explored in the lateral decubitus position.

Some areas of the lung (retroscapular, periclavicular and superior portions of the axilla) are hidden by anatomic structures. These regions could be explored through appropriate tilting of the probe but about $20 \%$ of the lung surface is not visualized on transthoracic ultrasound examination.

Certain anatomical characteristics in children, such as a thinner chest wall and smaller thoracic width and lung mass, facilitate ultrasound imaging and ensure goodquality images of the lung. In noncooperative young patients, the examination is more time consuming but is usually feasible. Performance of a chest ultrasound scan requires less skill than other sonographic scans (e.g. of the abdomen or heart) and the learning curve is faster. Bedetti et al. [10] have demonstrated that beginners are able to detect the presence of the pulmonary interstitial syndrome (IS) after fewer than 10 examinations and a total training time of $30 \mathrm{~min}$. Ultrasound diagnosis of lung consolidation may be considered as a basic sonographic technique with a steep learning curve [11]. For the evaluation of B-lines, it is recommended to set the focus at the level of the pleural line.

\section{LUS Compared with Other Methods in the Diagnosis and Follow-Up of CAP in Adults}

\section{Sonomorphology}

Sonomorphology of CAP may be divided into parenchymal, pleural and vascular criteria (table 1).

The most important parenchymal criterion is the positive air bronchogram within an echopoor area, which may be found in about $70-97 \%$ of cases $[9,12-14]$ (fig. 1), while among pleural criteria basal effusion was the most frequent detection (in about $34-61 \%$ cases) [9, 12-15]. Determination of vascularization is very helpful, especially for differential diagnosis, but it is not essential for the diagnosis of uncomplicated CAP. Table 2 gives an overview of studies involving sonography in the diagnosis of adult CAP.

\section{Differential Diagnosis}

Lung cancer, pulmonary embolism and atelectasis are the most important differential diagnoses of pneumonia.

Lung cancer may be accompanied by pneumonia following obstruction of the airways. In this case, no complete recovery will occur during the follow-up of pneumonia. Lung carcinoma normally has no positive air 

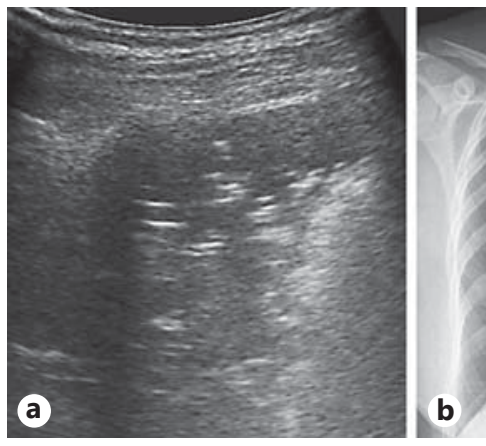

Fig. 1. A 28-year-old woman with clinical signs of pneumonia. a LUS of the left side reveals an echopoor lesion with typical positive air bronchogram. b Corresponding chest X-ray performed on the day of her hospital admission shows infiltration
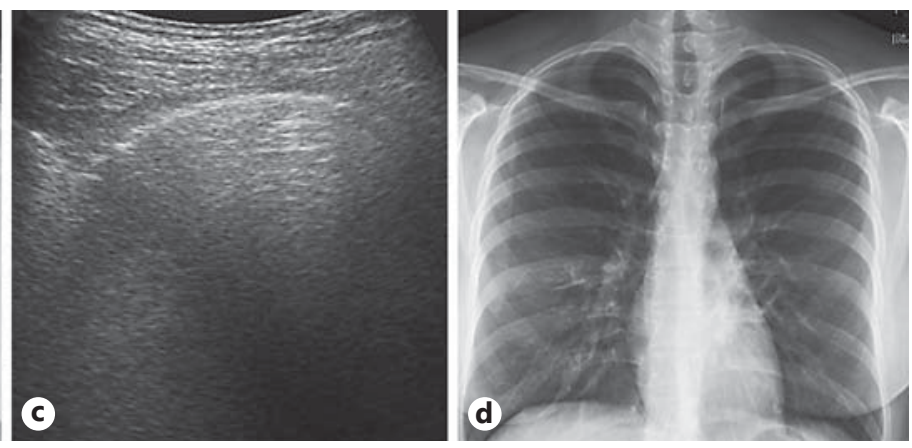

on both sides. c LUS of the left side on day 16 is normal, whereas chest X-ray on day 16 still shows residual disease on both sides $(\mathbf{d})$.

Table 1. Sonomorphology of adult CAP

\begin{tabular}{lll}
\hline Parenchymal criteria & Pleural criteria & Vascular criteria \\
\hline $\begin{array}{l}\text { Area of echopoor echogenicity and an } \\
\text { inhomogeneous echotexture with blurred } \\
\text { margins }\end{array}$ & $\begin{array}{l}\text { Pleural line attenuation corresponding } \\
\text { to the affected area }\end{array}$ & $\begin{array}{l}\text { Color Doppler sonography: enhanced, } \\
\text { tree-like vascularity }\end{array}$ \\
\hline $\begin{array}{l}\text { Positive air bronchogram: reflects residua of } \\
\text { air within consolidated areas }\end{array}$ & Localized pleural effusion & $\begin{array}{l}\text { Spectral curve analysis: pulmonary and } \\
\text { bronchial artery }\end{array}$ \\
\hline $\begin{array}{l}\text { Positive fluid bronchogram: reflects } \\
\text { fluid-filled airways }\end{array}$ & Basal pleural effusion & $\begin{array}{l}\text { Contrast-enhanced sonography: short } \\
\text { time to enhancement and marked extent } \\
\text { of enhancement }\end{array}$ \\
\hline
\end{tabular}

Necrotic areas within pneumonic lesions possible

Superficial fluid alveologram: subpleural echopoor region without bronchogram and fluid bronchogram

bronchogram. Malignancies are polycyclic, not well demarcated and sometimes infiltration into the thorax wall may be discovered that avoids breath-dependent motion of the lesion. In spectral curve analysis, various vessels are detectable, particularly new blood vessels in tumor tissue (neoangiogenesis).

Pulmonary embolism may also cause pneumonia due to embolic occlusion, which might be suspected if pneumonia is triangular. Characteristic sonographic signs of peripheral pulmonary embolism are multiple (mean 2-3), mostly triangular, hypoechoic, subpleural lesions with breath-dependent motion, which prefered the dorsal and basal regions of the lung $[19,20]$. Peripheral pulmonary embolism typically reveals no flow signals in color
Doppler sonography. Pleurisy and pleural lesions of unknown causes may be further differentiated by contrastenhanced sonography [21]. For further reading on this topic, we like to refer to the review by Kreuter et al. [22] in this Thematic Review Series.

Atelectasis, compressive atelectasis as well as resorptive atelectasis have to be differentiated from pneumonia. Compressive atelectasis is normally induced by a large pleural effusion and moves within the effusion like a 'waving hand'. It is moderately echoic, sharp demarcated and concave. Occasionally, it is possible to notice breath-dependent ventilation within the atelectasis. After thoracocentesis or diuretic therapy, compressive atelectasis becomes smaller or even disappears. Resorptive 
Table 2. Overview of studies on the sonographic diagnosis of CAP in adults $[16,17]$

\begin{tabular}{|c|c|c|c|c|c|c|}
\hline Feature & $\begin{array}{l}\text { Gehmacher et al. } \\
{[12], 1995} \\
(n=143)\end{array}$ & $\begin{array}{l}\text { Reissig and } \\
\text { Kroegel } \\
{[13], 2007} \\
(\mathrm{n}=30)\end{array}$ & $\begin{array}{l}\text { Parlamento et al. } \\
{[15], 2009} \\
(n=49)\end{array}$ & $\begin{array}{l}\text { Sperandeo et al. } \\
{[14], 2011} \\
(n=342)\end{array}$ & $\begin{array}{l}\text { Reissig et al. } \\
{[9], 2012} \\
(n=362)\end{array}$ & $\begin{array}{l}\text { Cortellaro et al. } \\
{[18], 2012} \\
(n=120)\end{array}$ \\
\hline Study design & $\begin{array}{l}\text { Patient with } \\
\text { X-ray-established } \\
\text { pneumonia }\end{array}$ & $\begin{array}{l}\text { Patient with } \\
\text { suspected CAP; } \\
\text { LUS follow-up } \\
\text { was required }\end{array}$ & $\begin{array}{l}\text { Patient with } \\
\text { suspected CAP } \\
\text { admitted to ED }\end{array}$ & $\begin{array}{l}\text { Inclusion of } \\
\text { X-ray-established } \\
\text { CAP; LUS } \\
\text { follow-up }\end{array}$ & $\begin{array}{l}\text { Patient with } \\
\text { suspected CAP; } \\
\text { LUS follow-up }\end{array}$ & $\begin{array}{l}\text { Patient with suspected } \\
\text { CAP in ED; CT if } \\
\text { clinically indicated } \\
(\mathrm{n}=30) \text {; most X-rays in } \\
\text { supine position; final } \\
\text { diagnosis as surrogate }\end{array}$ \\
\hline $\begin{array}{l}\text { Established } \\
\text { diagnosis of } \\
\text { pneumonia }\end{array}$ & $143(100 \%)$ & $\begin{array}{l}\text { LUS and X-ray } \\
\text { follow-up }\end{array}$ & $32 / 49(65.3 \%)$ & $342(100 \%)$ & $229 / 362(63.3 \%)$ & $81 / 120(67.5 \%)$ \\
\hline LUS positive & $127 / 143(88.8 \%)$ & Not reported & $31 / 32(96.9 \%)$ & $314 / 342(92 \%)$ & $211 / 229(92.1 \%)$ & $80 / 81(98 \%)$ \\
\hline $\mathrm{X}$-ray positive & Reference test & Reference test & $24 / 32(75 \%)$ & Reference test & $199 / 229(86.9 \%)$ & $54 / 81(67 \%)$ \\
\hline $\begin{array}{l}\text { Interstitial } \\
\text { pattern }\end{array}$ & Not reported & Not reported & $\begin{array}{l}22 / 32(68.8 \%) \\
\text { alveolar IS }\end{array}$ & Not reported & Not reported & $7 / 80(8.8 \%)$ \\
\hline $\begin{array}{l}\text { Positive air } \\
\text { bronchogram }\end{array}$ & $112 / 127(88.1 \%)$ & $32 / 32(97 \%)$ & $16 / 32(50 \%)$ & $220 / 314(70 \%)$ & $183 / 211(87.7 \%)$ & $\begin{array}{l}71 / 80(88.8 \%) \\
\text { (dynamic) }\end{array}$ \\
\hline $\begin{array}{l}\text { Fluid } \\
\text { bronchogram }\end{array}$ & Not reported & $0 / 33(0 \%)$ & Not reported & $100 / 314(31 \%)^{*}$ & $17 / 211(8.1 \%)$ & $28 / 80(35 \%)$ \\
\hline $\begin{array}{l}\text { Basal pleural } \\
\text { effusion in } \\
\text { LUS }\end{array}$ & $78 / 143(54.5 \%)$ & $20 / 33(61 \%)$ & $11 / 32(34.4 \%)$ & $120 / 34(35.1 \%)$ & $105 / 193(54.4 \%)$ & $31 / 80(38.8 \%)$ \\
\hline Size (LUS), $\mathrm{cm}$ & Not reported & $\begin{array}{l}3.37 \times 0.94 \text { and } \\
9.12 \times 4.53\end{array}$ & Not reported & $6.63 \times 3.11$ & $3.2 \times 3.7$ & Not reported \\
\hline $\begin{array}{l}\text { Sensitivity for } \\
\text { LUS }\end{array}$ & Not applicable & Not reported & Not reported & Not applicable & $\begin{array}{l}93.4 \% \text {; } \\
\text { CI: } 89.2-96.3 \%\end{array}$ & $\begin{array}{l}98 \% \\
\text { CI: } 93.3-99.9 \%\end{array}$ \\
\hline $\begin{array}{l}\text { Specificity for } \\
\text { LUS }\end{array}$ & Not applicable & Not reported & Not reported & Not applicable & $\begin{array}{l}97.7 \% ; \\
\text { CI: } 93.4-99.6 \%\end{array}$ & $\begin{array}{l}95 \% ; \\
\text { CI: } 82.7-99.4 \%\end{array}$ \\
\hline $\begin{array}{l}\text { Likelihood } \\
\text { ratio for } \\
\text { positive LUS }\end{array}$ & Not applicable & Not reported & Not reported & Not applicable & $\begin{array}{l}40.5 \\
\text { CI: } 13.2-123.9 \%\end{array}$ & $\begin{array}{l}19.3 \\
\text { CI: } 4.99-74.2 \%\end{array}$ \\
\hline $\begin{array}{l}\text { Likelihood } \\
\text { ratio for } \\
\text { negative LUS }\end{array}$ & Not applicable & Not reported & Not reported & Not applicable & $\begin{array}{l}0.07 \\
\text { CI: } 0.04-0.11 \%\end{array}$ & $\begin{array}{l}0.01 \\
\text { CI: } 0.002-0.09 \%\end{array}$ \\
\hline
\end{tabular}

$\mathrm{ED}=$ Emergency department; $*$ = patients with millimetric hypoechoic tubular formations.

atelectasis is a consequence of airway obstruction, mostly caused by cancer, exudate or aspiration. The accompanying effusion is small in comparison with the atelectasis, and thoracocentesis does not influence the size of resorptive atelectasis. Its echogenicity is comparable to that of the liver and the shape is very variable. Sometimes a fluid bronchogram reflecting exudate-filled airways may be detected. In contrast to pneumonia and compressive atelectasis, resorptive atelectasis does not reveal a dynamic air bronchogram [23]. Using contrast-enhanced sonography, resorptive atelectasis may be demarcated from the inducing cancer or metastasis [24], which is very helpful to determine the optimal site for tumor biopsy. 
Table 3. Overview of studies on sonographic diagnosis of pneumonia in children

\begin{tabular}{|c|c|c|c|c|}
\hline Feature & $\begin{array}{l}\text { Copetti and Cattarossi } \\
{[8], 2008} \\
(\mathrm{n}=79)\end{array}$ & $\begin{array}{l}\text { Iuri et al. [25] } \\
2009 \\
(\mathrm{n}=28)\end{array}$ & $\begin{array}{l}\text { Caiulo et al. [26] } \\
2013 \\
(n=102)\end{array}$ & $\begin{array}{l}\text { Shah et al. [27] } \\
2013 \\
(\mathrm{n}=200)\end{array}$ \\
\hline LUS positive & $60 / 60(100 \%)$ & $22 / 28(78 \%)$ & $88 / 89(98.8 \%)$ & $49 / 54(90.7 \%)$ \\
\hline $\mathrm{X}$-ray positive & $53 / 60(83.3 \%)$ & $28 / 28(100 \%)$ & $81 / 89(92 \%)$ & $36 / 54(66.6 \%)$ \\
\hline Sensitivity for LUS & Not reported & $91.7 \%$ & Not reported & $86 \%$ \\
\hline
\end{tabular}

\section{LUS Compared With X-Ray, CT and Auscultation}

The sensitivity of LUS in detecting CAP varies between 93.4 and $98 \%$, and the specificity between 97.7 and 95\%; the positive likelihood ratio ranges from 19.3 to 40.5 , and the negative likelihood ratio from 0.01 to $0.07[9,18]$. In several studies, LUS was at least as good as X-ray evaluation in detecting CAP $[8,9,15]$. Nevertheless, the gold standard CT was never used in all patients due to the hazards of radiation exposure $[8,9,15]$. Sonography detects peripheral pneumonic lesions, even small ones, whereas X-ray covers also central localized processes, but small ones may escape radiological detection. During the follow-up, LUS may already appear normal because the lesion no longer reaches the peripheral pleura. However, both techniques have advantages and disadvantages. They are comparable as well as complementary. It has been demonstrated that a combination of LUS and auscultation findings resulted in a higher positive (42.9, 95\% confidence interval, CI, 10.8$17.0)$ as well as in a lower negative likelihood ratio $(0.04$, CI 0.02-0.09) [9]. LUS enables the early detection of complications such as empyema and lung abscesses.

\section{LUS Compared with Other Methods in the Diagnosis and Follow-Up of CAP in Children}

At present, only a few papers have been published on this topic [8,25-27], but all studies have demonstrated that LUS is able to diagnose pneumonia in children and young adults with high accuracy (table 3 ). It will not completely replace chest radiography, but with increasing use and experience by ultrasonographers combined with improve- ments in LUS techniques, it has the potential to establish as a very important diagnostic imaging option for pneumonia, especially in children [28].

\section{Sonomorphology}

The ultrasonographic appearance of pneumonia does not differ between children and adults [11]. Pneumonia appears as a hypoechogenic area with poorly defined borders and with the presence of B-lines at the far-field margin. The pleural line is less echogenic in the area affected by lung consolidation and lung sliding is reduced or absent. In the case of consolidations, branching echogenic structures - representing air bronchograms - are seen in the infected area (fig. 2 and fig. 3 ). Air bronchograms may show intrinsic dynamic centrifugal movements due to breathing. This finding is called dynamic air bronchogram: it attests bronchial patency and rules out obstructive atelectasis. Multiple lenticular echoes, representing air trapped in the smaller airways, are also frequently observed. Fluid bronchograms, described in postobstructive pneumonia, are identified as anechoic tubular structures with hyperechoic walls but without color Doppler signals. Fluid bronchograms are frequently observed in pneumonia in children (fig. 4,5). Pleural effusion is easily detected on LUS and appears as an anechoic area in the pleural space. A honeycomb organization of fibrin is observed in pleural empyema (fig. 6).

\section{Differential Diagnosis}

Like in adults, pulmonary atelectasis may simulate pneumonia. The dynamic ultrasound signs are often very useful for the differential diagnosis and may be monitored 


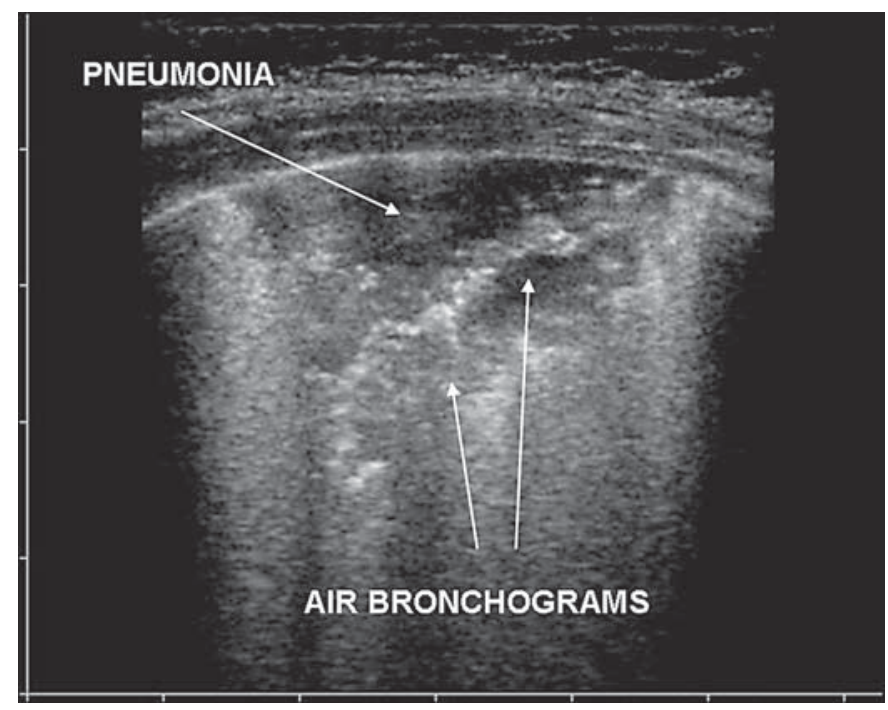

Fig. 2. Transverse thoracic scan of a 9-year-old child with clinically suspected pneumonia. LUS shows the presence of consolidation with evidence of air bronchograms.

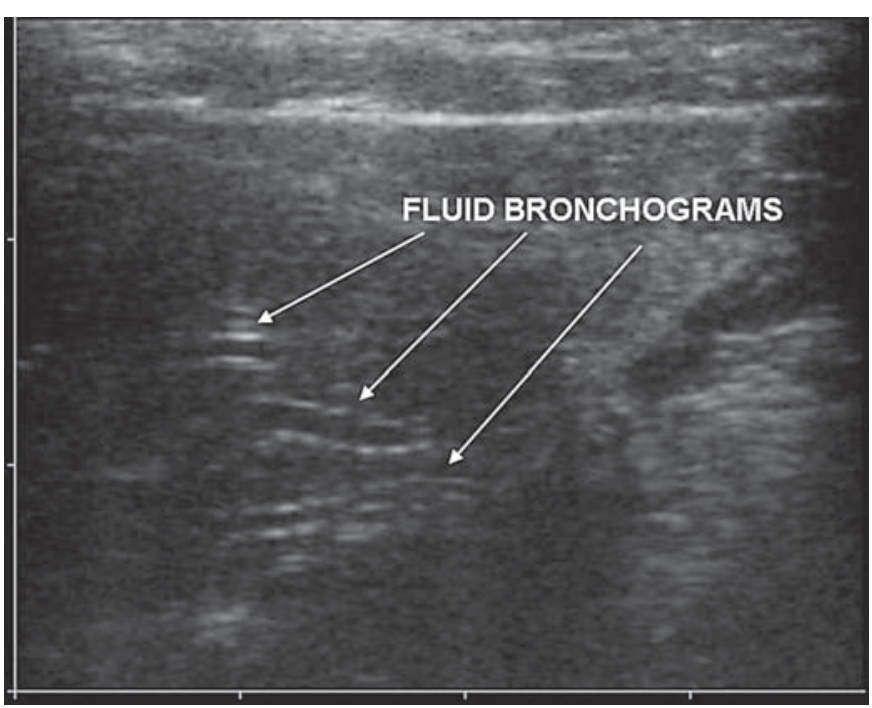

Fig. 4. Fluid bronchograms, which are frequently observed in postobstructive pneumonia, appear as anechoic tubular structures with hyperechoic walls without any color Doppler signal.

at bedside. Ultrasonographically, atelectasis is characterized by a liver-like appearance of the lung with 'lung pulse', absence of lung sliding and a parallel course of air bronchograms, in agreement with results in adult patients [29]. The evidence of dynamic air bronchograms rules out obstructive atelectasis [23]. Fluid bronchograms are often present.

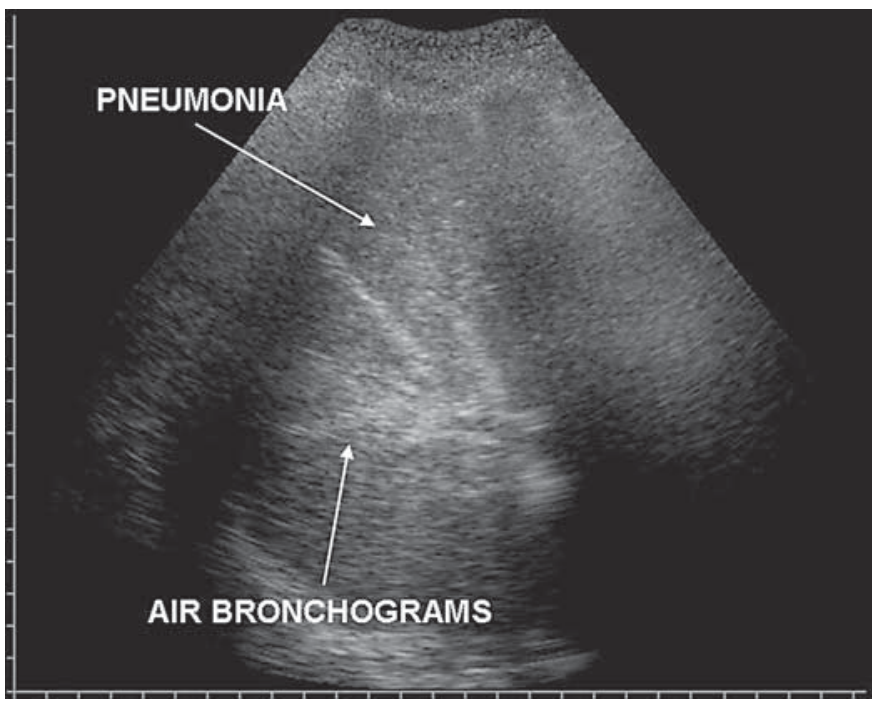

Fig. 3. Lobar pneumonia in an 11-year-old child. Air bronchograms are seen in the infected area as branching echogenic structures.

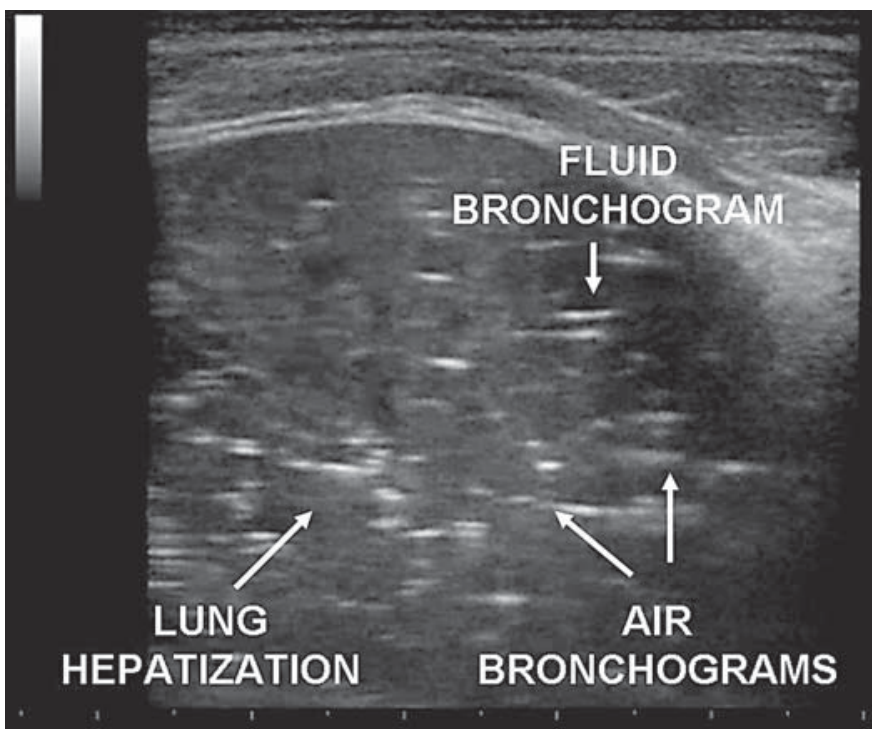

Fig. 5. Lobar pneumonia in a 10-year-old child admitted to the emergency department for fever and cough. LUS reveals air and fluid bronchograms within the affected area.

\section{LUS Compared with X-Ray and CT}

Children and infants with pneumonia may present with a number of clinical symptoms and signs, such as fever, cough and tachypnea. A minority of children present with fever of unknown origin and may have no respiratory symptoms or signs. In these cases, a ra- 


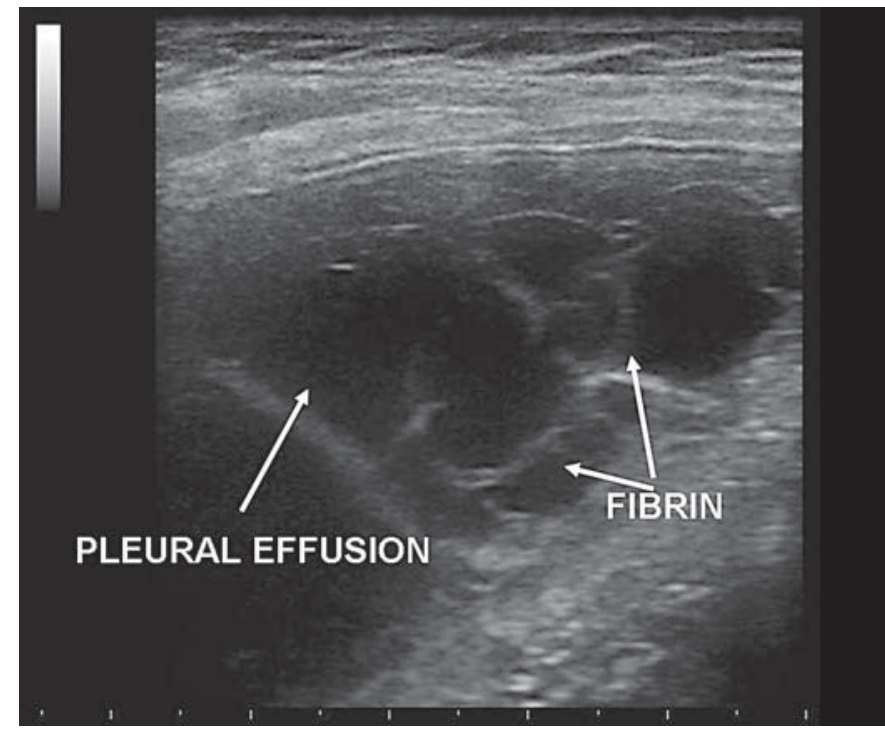

Fig. 6. A 7-year-old child with a complicated course of pneumonia with persistence of fever and high values of C-reactive protein. LUS shows a pleural empyema with honeycomb organization of fibrin within the effusion.

diological examination may be necessary. In the guidelines, chest X-ray is still considered to be the first imaging step for diagnosing pneumonia in children $[4,5$, 30]. CT has a high level of accuracy but cannot be used as a first-line radiological examination due to its high exposure to ionizing radiation, reduced availability and costs. In adults, LUS has been shown to be a very promising technique due to its high sensitivity in detecting pleural effusions, lung embolism, pneumonia, pneumothorax, IS and atelectasis [31], but research on these topics in children is scarce. Ultrasound examination can be done at the patient's bedside and repeated without any radiation risk. Due to these characteristics, LUS is an ideal tool for diagnosis as well as the detection of complications and for the follow-up of pneumonia.

LUS is a clinically useful diagnostic tool in pediatric patients with suspected pneumonia. The ultrasound signs of lung and pleural diseases described in adults are also found in pediatric patients. Although LUS is a clinically useful tool for the diagnosis of pneumonia, it does not rule out consolidations that do not reach the pleura [11]. These data suggest that in case of a clinical suspicion of pneumonia, a positive LUS excludes the need to perform chest radiography. Nevertheless, a negative chest radiograph does not rule out pneumonia.

Ultrasound in Pediatric Lung Diseases Revisited

\section{LUS Compared with Other Methods in the Diagnosis of Interstitial Lung Diseases}

\section{Diffuse Parenchymal Lung Diseases}

According to the American Thorax Society and European Respiratory Society, DPLD are classified into DPLD of known causes (e.g. drug induced), idiopathic interstitial pneumonia (e.g. idiopathic pulmonary fibrosis, IPF), granulomatous DPLD (e.g. sarcoidosis) and DPLD of other causes [32]. The main symptom in IPF patients is increasing dyspnea on exertion. Diagnosis is based on clinical history and examination, serological tests, as well as lung function, CT and, if necessary, bronchoscopy with bronchoalveolar lavage or transbronchial biopsy. In some rare cases, thoracic surgery is included in the differential diagnosis. Current studies show the significance of LUS in diagnosing interstitial lung diseases [33-37].

The most important ultrasound sign for interstitial diseases is B-lines. The generation of B-lines is still debated. It is supposed that the creation of B-lines depends on increased density of the lung due to a decrease in the amount of air, an increase in interstitial tissue or both. These phenomena generate an acoustic permeability of the pleural line that in normal conditions acts a specular reflector as a consequence of the high difference in acoustic impedance between the chest wall tissue and aerated lung $[38,39]$. Nevertheless, B-lines are artifacts and may also appear in the healthy lung [33].

In general, IS may be diffuse bilateral (e.g. pulmonary edema of various causes, interstitial pneumonia or pneumonitis, or DPLD) or focal (e.g. accompanying pneumonia or pneumonitis, atelectasis, pulmonary contusion or infarction, pleural disease or neoplasia). Furthermore, Blines may have a homogeneous or nonhomogeneous distribution and the localization as well as the gradient (ventral-dorsal/apical-caudal) and the alterations in the pleural line (fragmentation, irregularity and swelling) should be assessed for further differential diagnostic considerations. For DPLD (e.g. IPF), table 4 summarizes characteristic sonomorphologic features of DPLD (fig. 7).

In interstitial pneumonia, an interstitial LUS pattern combined with spared areas is strongly suggestive for viral pneumonia and correlates with the findings on CT scans $[40,41]$. Nevertheless, some studies lack the 'gold standard' for diagnosis or have a time lag between LUS and CT [37]. Using LUS, it is possible to detect and follow up interstitial abnormalities. Nevertheless, to determine the cause of the history of B-lines, clinical examination and sometimes follow-up and CT are necessary. 
Fig. 7. A 78-year-old man with clinical increasing dyspnea. a LUS reveals irregular pleural surface and multiple B-lines. b Corresponding chest $\mathrm{CT}$ shows typical features of IPF.
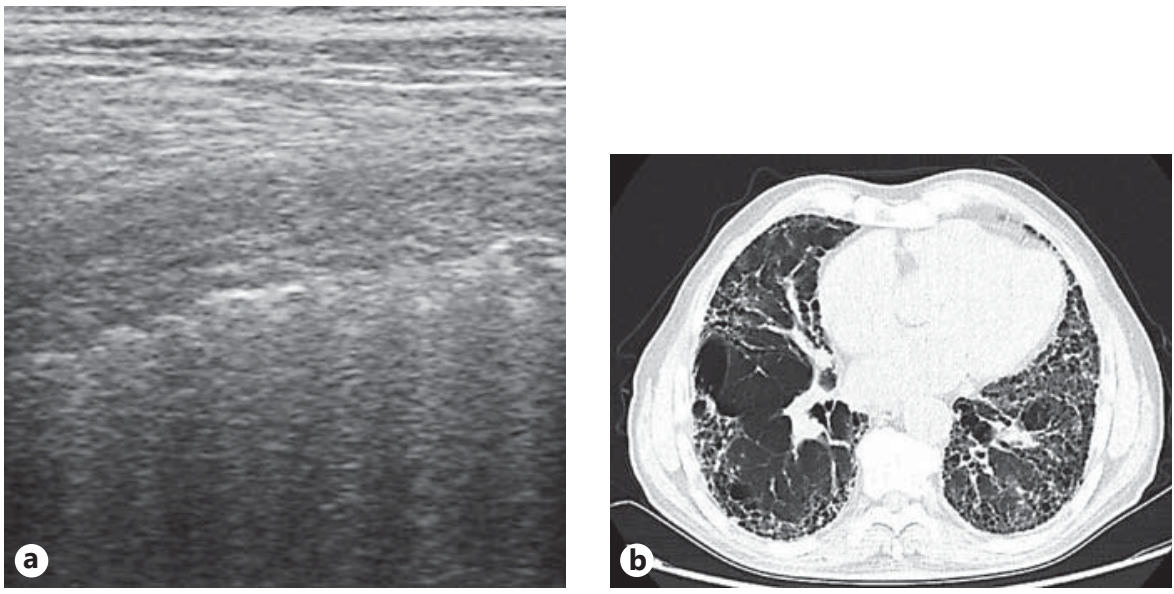

To date, the following issues remain open to discussion:

- counting of B-lines (8-zone technique vs. 28 rib interspaces) $[11,34]$;

- the effect of the ultrasound equipment, the scanner (convex or linear) and penetration depth used on the number of B-lines and pleural line abnormalities;

- differences in scoring systems between various studies ( $>6$ B-lines per scan; $\geq 3$ B-lines in a longitudinal plane between 2 ribs; $\geq 3$ B-lines in $\geq 2$ adjacent scanning sites or $>5$ B-lines) $[11,33,37]$.

In general, it has to be taken in account that counting of B-lines is best performed in real-time mode as they may disappear on a frozen image.

\section{Increase in Extravascular Lung Water: Acute Heart Failure and ARDS}

In acute cardiopulmonary clinical conditions, bilateral and diffuse B-lines are more frequently an ultrasonographic sign of increased extravascular lung water. The sensitivity of B-lines in detecting the increase in extravascular lung water is very high, ranging from 96.9 to $100 \%$ in different studies, and their absence in a dyspneic patient virtually rules out pulmonary edema $[42,43]$.

In critically ill patients, the differential diagnosis between acute cardiogenic pulmonary edema (APE) and ARDS may be very difficult [44]. Differential diagnosis using CT has been well described, although the accuracy of chest X-ray is unclear. Chest X-ray is a poor at detecting the cause or location of excess extravascular lung water [45].

The pathophysiology of ARDS is completely different from that of APE and this generates different pleuropulmonary ultrasound patterns with a different distribution
Table 4. Characteristic sonomorphologic features of DPLD (modified after [11])

Multiple, diffusely distributed, bilateral, nonhomogeneous B-lines (mostly in the lower lobes and dorsally)

B-line localization/distribution correlates with CT signs of fibrosis Pleural line abnormalities (irregular/fragmented) are detectable

Subpleural abnormalities (small echopoor lesions) may occur

Minor pleural effusion is possible

of IS $[11,42]$. In ARDS, the damage of the alveolar capillary membrane causes an early, diffuse, heterogeneous alveolar flooding ranging from a 'ground glass' appearance to lung consolidation. The heterogeneous involvement of the lungs in ARDS explains the presence of 'spared areas'. Pleural line abnormalities are very common in patients with ARDS and may be well visualized with a linear probe. It is possible to observe areas with a reduction or absence of 'lung sliding' and often areas in which B-lines are coalescent ('white lung') are observed. In addition, the 'lung pulse' sign could be observed. The pleural line appears irregular, thickened and coarse because of the presence of multiple small subpleural consolidations. Involvement of the pleural line is not homogeneous and corresponds to the distribution and degree of IS (fig. 8; table 5).

In contrast, APE is a hydrostatic edema and IS shows a homogeneous distribution involving both anterior and posterior lung fields. Superior lung fields might be less affected but 'spared areas' cannot be observed, which reflects the pathophysiology. B-lines initially prefer the lung 
Fig. 8. a In ARDS, IS is nonhomogeneous and this generates 'spared areas'. b In cardiogenic pulmonary edema, IS has a homogeneous distribution.

Fig. 9. a In ARDS, there are areas in which the pleural line appears irregular, thickened and coarse. b In cardiogenic pulmonary edema, the pleural line is regular.
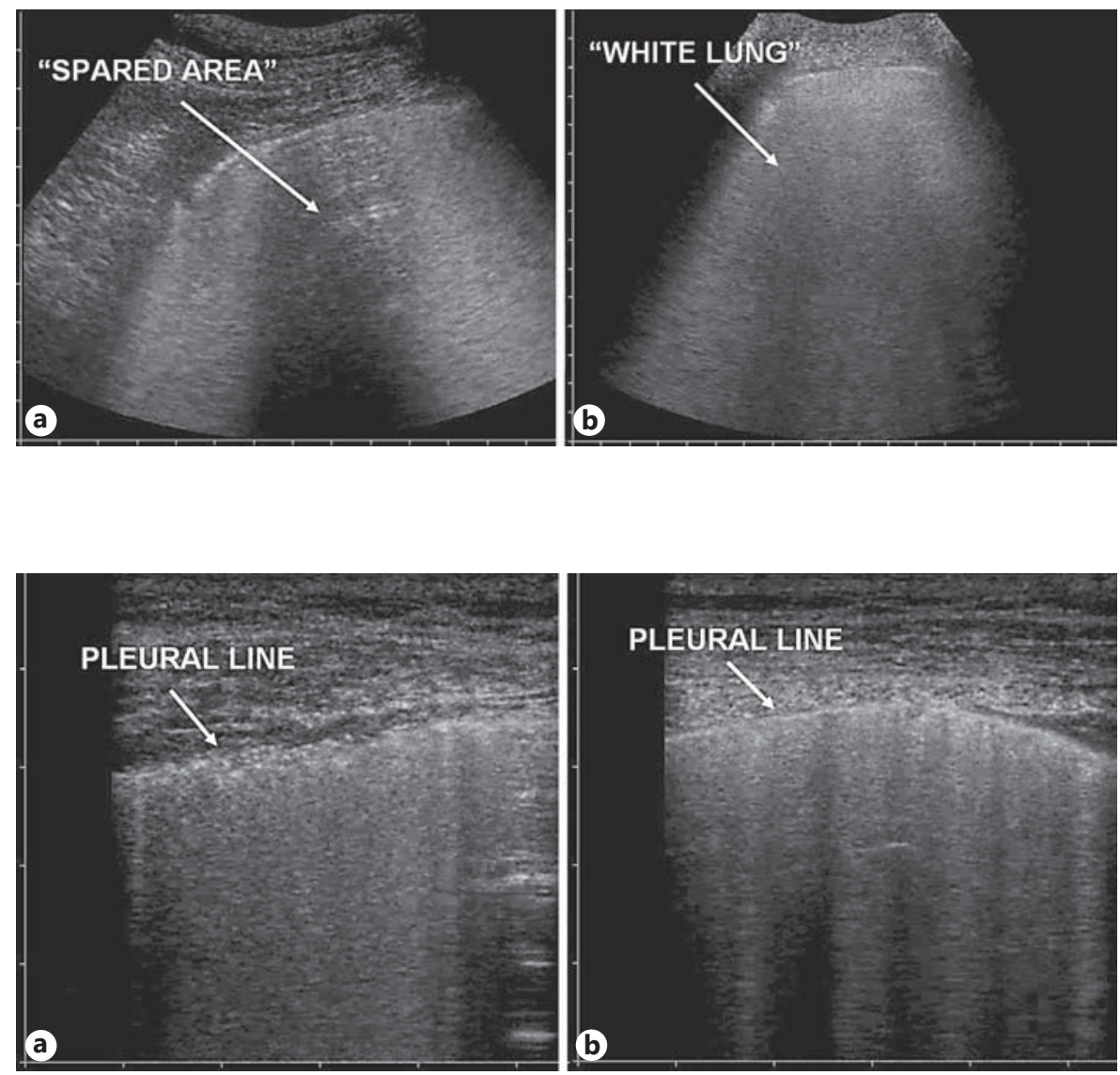

Table 5. Sonomorphological differentiation of DPLD, APE and ARDS

\begin{tabular}{llll}
\hline & DPLD & APE & ARDS \\
\hline Clinical setting & Chronic & Acute & Acute \\
\hline IS & Always present & Always present & Always present \\
\hline Distribution of IS & $\begin{array}{l}\text { Nonhomogeneous } \\
\text { distribution, mostly in the } \\
\text { dorsal and lower areas }\end{array}$ & $\begin{array}{l}\text { Bilateral and symmetric } \\
\text { distribution }\end{array}$ & $\begin{array}{l}\text { Nonhomogeneous } \\
\text { distribution, presence of } \\
\text { spared areas }\end{array}$ \\
\hline Effect of diuresis on B-lines & No effect & Reduction & No effect \\
\hline Pleural line abnormalities & Present, typical & Absent & Present, typical \\
\hline $\begin{array}{l}\text { Reduction or absence of } \\
\text { lung sliding }\end{array}$ & Absent & Absent & Present \\
\hline Lung pulse & Present & Absent & Present \\
\hline Consolidations & May occur & Absent & $\begin{array}{l}\text { Frequent in the posterior } \\
\text { areas }\end{array}$ \\
\hline Pleural effusion & Often localized effusions & Very frequent and large & Common but small
\end{tabular}

Ultrasound in Pediatric Lung Diseases Revisited 
bases but with increasing capillary venous pressure extend to the medium and superior fields. The pleural line is rarely involved and appears as a hyperechoic band without sliding impairment (fig. 9; table 5).

\section{Conclusion}

The published data show that LUS performs well in a lot of clinical scenarios. Nevertheless, at present, CT still represents the gold standard for most pulmonary diseases. However, in comparison with chest X-ray, especially in the critical care setting, LUS at bedside performs better than chest radiography in numerous cases.

LUS is an accurate tool in in the diagnosis of pneumonia in adults as well as in children. Regarding pneumonia, LUS is at least as accurate as chest radiography.

The presence of multiple diffuse bilateral B-lines on lung examination indicates IS. For further differential diagnosis, an integrated consideration of history, clinical examination, LUS (B-lines, their distribution as well as variations in the pleural line) and echocardiography should be performed. LUS is an excellent tool for IS screening. Especially in pulmonary edema, repeated LUS control examinations may reflect the dynamics of the disease under therapy and so LUS may serve as a therapy guide.

At present, LUS is not considered in any guideline for the diagnosis of CAP or IS. Nevertheless, we think that future guidelines should include LUS.

Ultrasound avoids the use of ionizing radiation. Therefore, the use of ultrasound - especially in pediatric patients - needs to be encouraged not just as a valid diagnostic alternative but as a necessary ethical choice. Further research regarding the role of color Doppler sonography, spectral curve analysis and contrast-enhanced ultrasound is necessary, especially with respect to differential diagnosis of lung consolidations and early detection of complications.

\section{Financial Disclosure and Conflicts of Interest}

All authors assert no conflicts of interest, neither financial nor nonfinancial, pertaining to this article.

\section{References}

1 Woodhead M, Blasi F, Ewig S, Huchon G, Ieven M, Ortqvist A, Schaberg T, Torres A, van der Heijden G, Verheij TJ; European Respiratory Society; European Society of Clinical Microbiology and Infectious Diseases: Guidelines for the management of adult lower respiratory tract infections. Eur Respir J 2005; 26:1138-1180.

$>2$ Hoffken G, Lorenz J, Kern W, Welte T, Bauer T, Dalhoff K, Dietrich E, Ewig S, Gastmeier P, Grabein B, Halle E, Kolditz M, Marre R, Sitter $\mathrm{H}$ : Epidemiology, diagnosis, antimicrobial therapy and management of communityacquired pneumonia and lower respiratory tract infections in adults. Guidelines of the Paul-Ehrlich-Society for Chemotherapy, the German Respiratory Society, the German Society for Infectiology and the Competence Network CAPNETZ Germany (in German). Pneumologie 2009;63:e1-e68.

$\checkmark 3$ Prayle A, Atkinson M, Smyth A: Pneumonia in the developed world. Paediatr Respir Rev 2011;12:60-69.

4 Harris M, Clark J, Coote N, Fletcher P, Harnden A, McKean M, Thomson A: British Thoracic Society Guidelines for the management of community acquired pneumonia in children: update 2011. Thorax 2011;66(suppl 2): ii1-ii23.

5 Bradley JS, Byington CL, Shah SS, Alverson B, Carter ER, Harrison C, Kaplan SL, Mace SE, McCracken GH Jr, Moore MR, St Peter SD,
Stockwell JA, Swanson JT, Pediatric Infectious Diseases Society and the Infectious Diseases Society of America: Executive summary: the management of community-acquired pneumonia in infants and children older than 3 months of age: clinical practice guidelines by the Pediatric Infectious Diseases Society and the Infectious Diseases Society of America. Clin Infect Dis 2011;53:617-630.

-6 Hazir T, Nisar YB, Qazi SA, Khan SF, Raza M, Zameer S, Masood SA: Chest radiography in children aged 2-59 months diagnosed with non-severe pneumonia as defined by World Health Organization: descriptive multicentre study in Pakistan. BMJ 2006;333:629.

7 Murphy CG, van de Pol AC, Harper MB, Bachur RG: Clinical predictors of occult pneumonia in the febrile child. Acad Emerg Med 2007; 14:243-249.

$>8$ Copetti R, Cattarossi L: Ultrasound diagnosis of pneumonia in children. Radiol Med (Torino) 2008;113:190-198.

$>9$ Reissig A, Copetti R, Mathis G, Mempel C, Schuler A, Zechner P, Aliberti S, Neumann R, Kroegel C, Hoyer H: Lung ultrasound in the diagnosis and follow-up of community-acquired pneumonia: a prospective, multicenter, diagnostic accuracy study. Chest 2012;142:965-972.

10 Bedetti G, Gargani L, Corbisiero A, Frassi F, Poggianti E, Mottola G: Evaluation of ultrasound lung comets by hand-held echocardiography. Cardiovasc Ultrasound 2006;4:34.
11 Volpicelli G, Elbarbary M, Blaivas M, Lichtenstein DA, Mathis G, Kirkpatrick AW, Melniker L, Gargani L, Noble VE, Via G, Dean A, Tsung JW, Soldati G, Copetti R, Bouhemad B, Reissig A, Agricola E, Rouby JJ, Arbelot C, Liteplo A, Sargsyan A, Silva F, Hoppmann R, Breitkreutz R, Seibel A, Neri L, Storti E, Petrovic T: International evidencebased recommendations for point-of-care lung ultrasound. Intensive Care Med 2012; 38:577-591.

12 Gehmacher O, Mathis G, Kopf A, Scheier M: Ultrasound imaging of pneumonia. Ultrasound Med Biol 1995;21:1119-1122.

13 Reissig A, Kroegel C: Sonographic diagnosis and follow-up of pneumonia: a prospective study. Respiration 2007;74:537-547.

14 Sperandeo M, Carnevale V, Muscarella S, Sperandeo G, Varriale A, Filabozzi P, Piattelli ML, D’Alessandro V, Copetti M, Pellegrini F, Dimitri L, Vendemiale G: Clinical application of transthoracic ultrasonography in inpatients with pneumonia. Eur J Clin Invest 2011;41:1-7.

15 Parlamento S, Copetti R, Di Bartolomeo S: Evaluation of lung ultrasound for the diagnosis of pneumonia in the ED. Am J Emerg Med 2009;27:379-384.

16 Reissig A, Gramegna A, Aliberti S: The role of lung ultrasound in the diagnosis and followup of community-acquired pneumonia. Eur J Intern Med 2012;23:391-397. 
$\checkmark 17$ Reissig A, Görg C: Pneumonie und diffus parenchymale Lungenerkrankungen im Lungenultraschall. Pneumologe 2012;9:444-451.

- 18 Cortellaro F, Colombo S, Coen D, Duca PG: Lung ultrasound is an accurate diagnostic tool for the diagnosis of pneumonia in the emergency department. Emerg Med J 2012;29:1923.

19 Reissig A, Heyne JP, Kroegel C: Sonography of lung and pleura in pulmonary embolism: sonomorphologic characterization and comparison with spiral CT scanning. Chest 2001; 120:1977-1983.

20 Mathis G, Blank W, Reissig A, Lechleitner P, Reuss J, Schuler A, Beckh S: Thoracic ultrasound for diagnosing pulmonary embolism. A prospective multicenter study of $352 \mathrm{pa}-$ tients. Chest 2005;128:1531-1538.

-21 Goerg C, Bert T, Goerg K: Contrast-enhanced sonography for differential diagnosis of pleurisy and focal pleural lesions of unknown cause. Chest 2005;128:3894-3899.

22 Kreuter M, Mathis G: Emergency ultrasound of the chest. Respiration 2014;87:8997.

23 Lichtenstein D, Meziere G, Seitz J: The dynamic air bronchogram. A lung ultrasound sign of alveolar consolidation ruling out atelectasis. Chest 2009;135:1421-1425.

24 Goerg C: Transcutaneous contrast-enhanced sonography of pleural-based pulmonary lesions. Eur J Radiol 2007;64:213-221.

25 Iuri D, De Candia A, Bazzocchi M: Evaluation of the lung in children with suspected pneumonia: usefulness of ultrasonography. Radiol Med (Torino) 2009;114:321-330.

-26 Caiulo VA, Gargani L, Caiulo S, Fisicaro A, Moramarco F, Latini G, Picano E, Mele G: Lung ultrasound characteristics of community-acquired pneumonia in hospitalized children. Pediatr Pulmonol 2013;48:280287.
27 Shah VP, Tunik MG, Tsung JW: Prospective evaluation of point-of-care ultrasonography for the diagnosis of pneumonia in children and young adults. JAMA Pediatr 2013;167: 119-125.

28 Darge K, Chen A: Ultrasonography of the lungs and pleurae for the diagnosis of pneumonia in children: prime time for routine use. JAMA Pediatr 2013;167:187-188.

29 Lichtenstein DA, Lascols N, Prin S, Meziere G: The 'lung pulse': an early ultrasound sign of complete atelectasis. Intensive Care Med 2003;29:2187-2192.

30 Korppi M: Diagnosis and treatment of community-acquired pneumonia in children. Acta Paediatr 2012;101:702-704.

31 Reissig A, Copetti R, Kroegel C: Current role of emergency ultrasound of the chest. Crit Care Med 2011;39:839-845.

32 American Thoracic Society; European Respiratory Society: American Thoracic Society/ European Respiratory Society International Multidisciplinary Consensus Classification of the Idiopathic Interstitial Pneumonias. This joint statement of the American Thoracic Society (ATS), and the European Respiratory Society (ERS) was adopted by the ATS Board of Directors, June 2001 and by the ERS Executive Committee, June 2001. Am J Respir Crit Care Med 2002;165:277-304.

33 Reissig A, Kroegel C: Transthoracic sonography of diffuse parenchymal lung disease: the role of comet tail artifacts. J Ultrasound Med 2003;22:173-180.

34 Gargani L, Doveri M, D’Errico L, Frassi F, Bazzichi ML, Delle Sedie A, Scali MC, Monti S, Mondillo S, Bombardieri S, Caramella D, Picano E: Ultrasound lung comets in systemic sclerosis: a chest sonography hallmark of pulmonary interstitial fibrosis. Rheumatology (Oxford) 2009;48:1382-1387.

35 Copetti R, Copetti P, Soldati G: Ultrasound pattern in pulmonary fibrosis: have the vertical artifacts disappeared? Ultrasound Med Biol 2010;36:356-357; author reply 357.
36 Moazedi-Fuerst FC, Zechner PM, Tripolt NJ, Kielhauser SM, Brickmann K, Scheidl S, Lutfi A, Graninger WG: Pulmonary echography in systemic sclerosis. Clin Rheumatol 2012;31: 1621-1625.

37 Barskova T, Gargani L, Guiducci S, Randone SB, Bruni C, Carnesecchi G, Conforti ML, Porta F, Pignone A, Caramella D, Picano E, Cerinic MM: Lung ultrasound for the screening of interstitial lung disease in very early systemic sclerosis. Ann Rheum Dis 2013;72:390395.

38 Soldati G, Copetti R, Sher S: Sonographic interstitial syndrome: the sound of lung water. J Ultrasound Med 2009;28:163-174.

39 Wojtczak JA, Wood RW: High-frequency ultrasound in ex vivo animal lungs in pulmonary edema. J Anesthesiol Clin Sci 2013;2:21.

-40 Testa A, Soldati G, Copetti R, Giannuzzi R, Portale G, Gentiloni-Silveri N: Early recognition of the 2009 pandemic influenza A (H1N1) pneumonia by chest ultrasound. Crit Care 2012;16:R30.

41 Volpicelli G, Frascisco MF: Sonographic detection of radio-occult interstitial lung involvement in measles pneumonitis. Am J Emerg Med 2009;27:128.e1-128.e3.

42 Copetti R, Soldati G, Copetti P: Chest sonography: a useful tool to differentiate acute cardiogenic pulmonary edema from acute respiratory distress syndrome. Cardiovasc Ultrasound 2008;6:16

43 Lichtenstein DA, Meziere GA: Relevance of lung ultrasound in the diagnosis of acute respiratory failure: the blue protocol. Chest 2008;134:117-125.

44 Ranieri VM, Rubenfeld GD, Thompson BT, Ferguson ND, Caldwell E, Fan E, Camporota L, Slutsky AS: Acute respiratory distress syndrome: the Berlin definition. JAMA 2012;307: 2526-2533.

45 Bouhemad B, Zhang M, Lu Q, Rouby JJ: Clinical review: bedside lung ultrasound in critical care practice. Crit Care 2007;11:205. 